\title{
BMJ Positive associations between open consumerism and tobacco and alcohol use in early adolescence: cross-sectional study
}

\author{
Helen N Sweeting, Abita Bhaskar, Kate Hunt
}

To cite: Sweeting HN, Bhaskar A, Hunt K. Positive associations between consumerism and tobacco and alcohol use in early adolescence: cross-sectional study. BMJ Open 2012;2: e001446. doi:10.1136/ bmjopen-2012-001446

- Prepublication history and additional material for this paper are available online. To view these files please visit the journal online (http://dx. doi.org/10.1136/bmjopen2012-001446).

Received 8 May 2012 Accepted 21 August 2012

This final article is available for use under the terms of the Creative Commons Attribution Non-Commercial 2.0 Licence; see http://bmjopen.bmj.com

MRC/CSO Social and Public Health Sciences Unit, Glasgow, UK

\section{Correspondence to} Dr Helen Sweeting; Helen@ sphsu.mrc.ac.uk

\section{ABSTRACT}

Background: There is concern about the negative impact of modern consumer culture on young people's mental health, but very few studies have investigated associations with substance use. In those which have, positive associations have been attributed to attempts to satisfy the unmet needs of more materialistic individuals.

Objectives: This study examines associations between different dimensions of consumerism and tobacco and alcohol use among Scottish early adolescents.

Design: Cross-sectional study.

Setting and participants: 2937 (92\% of those eligible) secondary school pupils (ages 12-14) completed questionnaires in examination conditions. Analyses were restricted to those with complete data on all relevant variables ( $N=2736$ smoking; $N=2737$ drinking).

Measures: Dependent variables comprised ever smoking and current drinking. Measures of consumerism comprised number of 'premium' (range 0-7) and 'standard' (range 0-5) material possessions and three Consumer Involvement subscales, 'dissatisfaction', 'consumer orientation' and 'brand awareness' (each range 3-12). Analyses also included school-year group and family affluence.

Results: Ever smoking and current drinking were both more prevalent among adolescents with more 'premium' and 'standard' material possessions, greater consumer 'dissatisfaction' and 'brand awareness' (mutually adjusted analyses including school-year group and family affluence). The strongest relationships occurred for 'brand awareness': for each unit increase in 'brand awareness' the ORs $(95 \% \mathrm{Cl})$ of ever smoking were 1.17 (1.08 to $1.26)$ and 1.23 (1.14 to 1.33) in males and females, respectively; and those for drinking were 1.15 (1.08 to 1.23 ) and 1.21 (1.13 to 1.30). 'Brand awareness' had an equal or stronger relationship with both smoking and drinking than did family affluence.

Conclusions: These results suggest aassociations between consumerism and both smoking and drinking might arise because adolescent identities incorporate both consumerism and substance use, or be the result of promotion (indirectly in the case of tobacco) linking consumerist or aspirational lifestyles with these behaviours.

\section{ARTICLE SUMMARY}

Article focus

- Studies conducted since the mid-1980s have shown consumerism to be associated with reduced well-being among children, adolescents and adults.

- Almost no studies have examined relationships between consumerism and substance use, and none have determined whether particular aspects of consumerism might have stronger associations with substance use than others.

- This study of Scottish early adolescents examines associations between different aspects of consumerism and tobacco and alcohol use, separately for males and females.

Key messages

- Smoking and drinking were both more likely among more consumer-oriented adolescents (those with greater numbers of modern consumer goods and greater consumer 'dissatisfaction', 'consumer orientation' and 'brand awareness'). Associations were generally similar for males compared with females and those from low compared with high family affluence backgrounds.

- 'Brand awareness' had an equal or stronger relationship with both smoking and drinking than did family affluence.

- More consumerist adolescents may be susceptible to both indirect tobacco marketing and imagery and more direct marketing of alcohol.

Strengths and limitations of this study

- Our analysis was conducted on a large, representative sample of early adolescents attending mainstream schooling.

- Cross-sectional data limit definitive conclusions about causation. However, our results are consistent with the small number of other studies which have found associations between consumerist values and adolescent substance use. 


\section{INTRODUCTION}

Tobacco smoking and alcohol use contribute to premature mortality and chronic ill-health. ${ }^{2}$ Smoking onset largely occurs during adolescence, and adolescents rapidly show signs of addiction after smoking initiation. ${ }^{3}$ Similarly, adolescence is a time of experimentation with alcohol and there are concerns about the increase in drinking in UK adolescents in recent years. ${ }^{4}$ This underlines the importance of addressing factors which promote smoking and drinking uptake in adolescents, to minimise future costs to individual and public health. One such factor may be modern consumer culture (henceforth consumerism), but to date, this has received relatively little research attention.

There is both academic ${ }^{5}$ and lay $^{6}$ concern about the impact of consumerism on health. Consumerism has been equated with a shift from intrinsic to external goals related to possessions, status and 'external trappings', ${ }^{7}$ and a number of studies conducted since the mid-1980s have shown it to be associated with reduced well-being among both adults ${ }^{8-10}$ and children or adolescents, ${ }^{11-13}$ including the sample of early adolescents on which the analyses presented here are based. ${ }^{14}$ However, very few studies have examined relationships between consumerism and substance use. One study from the USA provides evidence that consumerism is related to smoking, alcohol and cannabis use in 14 to 18 -year-olds, ${ }^{15}$ and another reports an association with alcohol use in 10 to 18-year-olds. ${ }^{16}$ Among 18 to 21-year-old Belgian students, a substance use scale (combining smoking, drinking and drug use) was negatively related to 'intrinsic values' and positively related to 'extrinsic values' relating to financial success and physical appearance. ${ }^{17}$ Finally, a study of Chinese 14 to 19-year-olds found positive associations, cross-sectionally and prospectively, between consumerism and scores on a self-reported risky behaviour questionnaire, one component of which was alcohol and/or drug use. ${ }^{18}$ It has been suggested that these associations may reflect attempts to satisfy the unmet needs of more materialistic individuals, ${ }^{15}$ in a manner akin to self-medication. ${ }^{17}$

Consumerism has been measured in a variety of ways among both adults and children or young people, including scales representing dimensions such as possessiveness and envy, ${ }^{8}$ desires for possessions or wealth, ${ }^{9}$ consumer involvement $^{11}$ and number of material possessions. ${ }^{19}$ Although most studies employ an overall 'consumerism' score, there is evidence that certain aspects (eg, 'envy' or 'dissatisfaction') may have stronger associations with wellbeing than others. ${ }^{811} 131420$ In addition, a study of early teenagers in the USA and the UK (using the same Consumer Involvement scale as in the analyses presented here) found distinct associations between different dimensions of consumerism and outside school activities. In particular, electronic media use and listening to music had much stronger associations with acquisition-focused and brand-focused aspects of consumerism than with consumerist dissatisfaction. ${ }^{13}$ It is therefore also possible that different dimensions of consumerism may vary in their associations with tobacco and alcohol use. Thus promotions, including glamourised images linking consumerist or aspirational lifestyles with smoking or drinking, might mean associations between these behaviours and acquisition-focused and/or brand-focused aspects of consumerism are stronger than those between smoking and drinking and consumerist dissatisfaction.

This study examines the associations between several measures of consumerism (number of 'premium' and 'standard' material possessions and three Consumer Involvement subscales) and smoking and drinking among a large sample of Scottish early adolescents. We include both smoking and drinking to examine whether they are associated with consumerism in different ways, since there are differences both in the legal position on commercial promotion of these two products and in their prevalence. In the UK, direct advertising of alcohol is permitted, while that of tobacco is not, and although it has been argued that both smoking and drinking are 'deviant behaviours' in adolescence, ${ }^{21}$ drinking is much more prevalent and likely to be regarded as part of a normal and fun existence. $^{22}$ We also examine variations in the associations according to gender and family affluence. Despite gender convergence in young people's drinking, men still continue to drink more, and in more detrimental ways, than women, ${ }^{23} 24$ and both smoking-related and alcohol-related deaths account for a substantial proportion of gender differences in mortality across Europe. ${ }^{25}$ It is therefore important to assess whether there may also be gender differences in vulnerability to potential early influences on the uptake of smoking and drinking. Existing evidence of differences between socio-economic groups in relationships between consumerism and well-being ${ }^{20}{ }^{26}$ raises the possibility of similar differences in respect of relationships between consumerism and substance use. Finally, multivariate analyses allow for examination of the independent associations which family affluence, compared with consumerism, has with smoking and drinking.

\section{METHODS}

\section{Design and sample}

We conducted self-completion surveys in examination-type conditions within seven Scottish Secondary (state-funded, mainstream) schools in early 2010. To maximise representativeness, we selected schools with different socioeconomic catchments (as indicated by the proportion of pupils in receipt of free school meals) from two urban and semirural areas in Scotland's central belt. Within the seven selected schools, all pupils in Secondary 1-3 (S1-S3, ages 12-14) were invited to participate via letters sent to parents, including opt-out parental consent forms. Informed written (opt-in) consent was obtained from pupils before questionnaire completion. The study received approval from the University of Glasgow Faculty of Law, Business and Social Sciences Ethics Committee, participating local education authorities and schools. 
The total sample comprised 2937 (92\% of the eligible sample of 3189). The majority of non-response was attributable to school absence on the day of the survey; only 11 parents and 15 pupils refused consent. Mean (SD) ages were $12.0(0.33)$ years in $\mathrm{S} 1,13.0(0.29)$ in $\mathrm{S} 2$ and $14.0(0.34)$ in S3.

\section{Measures}

Responses to the question 'how many cigarettes have you smoked in your life' were dichotomised to neversmoker ('none') and ever-smokers ('just a few puffs', '1-19 cigarettes', '20-100', 'more than 100'). Responses to 'how many drinks do you usually drink at one time' were dichotomised into non-drinkers ('I never drink alcohol', 'less than 1 drink') and current drinkers ('1-2 drinks', '3-4', '5-6', 'more than 6').

Pupils indicated whether or not they owned each of 12 material possessions (generated during questionnaire development via informal discussions with young adolescents about possessions which they considered desirable). For the purpose of analysis, items which were at the time more expensive or recently released, were categorised as 'premium' (Xbox 360, PS3 or Wii; PSP; IPod; IPod dock; own laptop; LCD TV in bedroom; touch-screen mobile phone -range $=0-7$, mean $=4.1, \mathrm{SD}=1.7$ ) and the remaining items as 'standard' (any other games console; any other MP3 player; own PC; any other TV in bedroom; any other mobile phone-range $=0-5$, mean $=2.7, \mathrm{SD}=1.2$ ).

Pupils also rated their agreement with 16 statements (4 point scale) based on a 'Consumer Involvement' scale originally administered to around 300 American 10 to 13 -year-olds. ${ }^{11}$ Previous studies have suggested that this scale has a three-factor structure ${ }^{11} 13$ and that an abridged nine-item variant (three items per factor) is psychometrically superior to the full scale in both US and UK samples. ${ }^{13}$ Similar confirmatory factor analysis among our sample found the items with the highest loadings on the three factors were identical to those in an earlier UK sample (see online supplementary table S1). Following previous studies, ${ }^{13}$ three Consumer Involvement subscales, each with ranges $3-12$, were therefore constructed: 'dissatisfaction' (the sum of responses to 'I wish my family could afford to buy me more of what I want', 'I wish my parents gave me more money to spend' and 'I wish my parents earned more money'-mean $=6.4, \quad \mathrm{SD}=2.2)$; 'consumer orientation' ('I usually have something in mind that I want to buy or get', 'I want to make a lot of money when I grow up' and 'when I go somewhere, I usually like to buy something'-mean=9.8, $\mathrm{SD}=1.5)$; and 'brand orientation' ('brand names matter to me', 'I like clothes with popular labels' and 'being cool is important to me'mean=8.1, $\mathrm{SD}=2.2$ ). Correlations between the subscales were 'dissatisfaction' and 'consumer orientation' $\mathrm{r}=0.252$; 'dissatisfaction' and 'brand awareness' $\mathrm{r}=0.172$; 'consumer orientation' and 'brand awareness' $r=0.395$.

Family affluence ${ }^{27}$ was derived via items in respect of: number of family cars, vans or trucks; having own (not shared) bedroom; number of family computers and number of family holidays in the past year. In line with the majority of studies which have used this measure, ${ }^{27}$ the resulting scale was collapsed into low (scale scores 0-3), medium (4-5) and high (6-7) affluence categories.

\section{Analyses}

Analyses were conducted via Stata V.11.0. We used a series of logistic regression analyses including interactions to identify any significant differences by gender or family affluence in the associations between the five measures of consumerism and smoking or drinking. First, to determine whether associations differed by gender, models entered: (1) 'premium' possessions, gender, 'premium' possessions by gender; (2) 'standard' possessions, gender, 'standard' possessions by gender; (3) 'dissatisfaction', 'gender', 'dissatisfaction' by gender; etc, for each substance (ie, five models for smoking and five for drinking). Of these, three interactions were (near) significant $(\mathrm{p}<0.10$-identified on table 2$)$. The exercise was then repeated, replacing gender with family affluence (one significant interaction-'consumer orientation' in respect of smoking, $\mathrm{p}=0.058$ for medium compared with low and $\mathrm{p}=0.046$ for high compared with low family affluence). Given some evidence of gender differences, we conducted all subsequent analyses separately for males and females.

Descriptive bivariate analyses examined the proportions of ever-smokers and drinkers according to school-year and family affluence category and the mean material possessions and Consumer Involvement subscale scores for ever-smokers and never-smokers and for current drinkers and non-drinkers. Logistic regression was used to determine both the unadjusted and mutually adjusted relationships which material possessions and the Consumer Involvement subscales had with smoking and drinking. These analyses also included school-year group and family affluence. Thus, the mutually adjusted models entered school-year group, family affluence, 'premium' possessions, 'standard' possessions, 'dissatisfaction', 'consumer orientation' and 'brand awareness' all together in respect of both smoking and drinking. Robust SEs were generated via the Stata survey command to account for the clustering within school classes. Since weighting the data according to school response rate made no difference to the results, analyses are based on unweighted data. Both unadjusted and adjusted analyses were conducted on those with complete data on all relevant variables, thus reducing the sample sizes to 2736 in respect of smoking and 2737 in respect of drinking. There were no significant differences in respect of family affluence between the full and analysed samples $(\mathrm{p}=.701)$.

\section{RESULTS}

One-fifth of the sample $(19.7 \%$ males and $22.2 \%$ females) had ever smoked and two-fifths (40\% males, 
$40.7 \%$ females) reported drinking one or more alcoholic drinks on a usual drinking occasion (table 1).

As expected, rates of smoking and drinking increased with age (here indicated by school-year group). For smoking, these increases with year group were greater for females than males (table 2). Socio-economic inequalities in smoking were well-established: $16.2 \%$ of males and $20.9 \%$ of females from the most affluent backgrounds had ever smoked, as compared with $29 \%$ and $33.6 \%$ of males and females from the least affluent backgrounds.

Ever smokers and current drinkers had higher mean numbers of both 'premium' and 'standard' possessions and higher scores on all three of the Consumer Involvement subscales. Associations between Consumer Involvement and both smoking and drinking were somewhat stronger for females, although the gender difference was only significant $(\mathrm{p}<.05)$ for the 'dissatisfaction' subscale in respect of drinking.

In mutually adjusted analyses, the relationships which both ever smoking and current drinking had with family affluence were strengthened, while those with 'consumer orientation' were weakened to non-significance (table 2, right-hand section). The size of the other associations changed little. Examination of the t-statistics shows that relationships between family affluence and current drinking were less significant than those seen between 'premium' possessions, 'dissatisfaction' or 'brand awareness' and drinking. Family affluence also had an equal (males) or less (females) significant relationship with ever smoking than did 'brand awareness'. For both males and females, the most significant effects, apart from those in respect of year group, occurred in relation to number of 'premium' possessions (for drinking) and the Consumer Involvement subscale 'brand awareness' (for both smoking and drinking).

Sensitivity analyses, conducted in order to test the effects of family affluence when entered as a continuous variable, rather than the collapsed low, medium and high affluence categories, showed almost identical results (see online supplementary table S2). Family affluence had a markedly less significant relationship with

Table 1 Ever smoking and current drinking overall and according to school-year group, family affluence, number of 'premium' and 'standard' possessions and Consumer Involvement subscales-males and females

\begin{tabular}{|c|c|c|c|c|}
\hline \multirow[b]{2}{*}{ Ever smoker } & \multicolumn{2}{|l|}{ Males } & \multicolumn{2}{|l|}{ Females } \\
\hline & $\begin{array}{l}\text { Ever smoker } \\
\mathrm{N}(\text { row \%) }\end{array}$ & $\begin{array}{l}\text { Never smoker } \\
\mathbf{N}(\text { row \%) }\end{array}$ & $\begin{array}{l}\text { Ever smoker } \\
\mathrm{N} \text { (row \%) }\end{array}$ & $\begin{array}{l}\text { Never smoker } \\
\mathrm{N} \text { (row \%) } \\
\end{array}$ \\
\hline Overall & $272(19.7)$ & $1107(80.3)$ & $301(22.2)$ & $1056(77.8)$ \\
\hline $\begin{array}{l}\text { Secondary } 1 \text { school-year* } \\
\text { Secondary } 2 \\
\text { Secondary } 3\end{array}$ & $\begin{array}{r}49(11.5) \\
81(17.1) \\
142(29.5)\end{array}$ & $\begin{array}{l}376(88.5) \\
392(82.9) \\
339(70.5)\end{array}$ & $\begin{array}{r}44(9.7) \\
88(19.5) \\
169(37.3)\end{array}$ & $\begin{array}{l}408(90.3) \\
364(80.5) \\
284(62.7)\end{array}$ \\
\hline $\begin{array}{l}\text { Low family affluence } \\
\text { Medium family affluence } \\
\text { High family affluence }\end{array}$ & $\begin{array}{r}42(29.0) \\
115(21.9) \\
115(16.2)\end{array}$ & $\begin{array}{l}103(71.0) \\
410(78.1) \\
594(83.8)\end{array}$ & $\begin{array}{r}40(33.6) \\
116(21.3) \\
145(20.9)\end{array}$ & $\begin{array}{r}79(66.4) \\
429(78.7) \\
548(79.1)\end{array}$ \\
\hline $\begin{array}{l}\text { Premium possessions } \\
\text { Standard possessions } \\
\text { Dissatisfaction } \\
\text { Consumer orientation } \\
\text { Brand awareness }\end{array}$ & $\begin{array}{c}\text { Mean (SD) } \\
4.4(1.8) \\
2.9(1.3) \\
7.0(2.3) \\
10.1(1.4) \\
9.1(2.1)\end{array}$ & $\begin{array}{c}\text { Mean (SD) } \\
4.1(1.8) \\
2.7(1.3) \\
6.5(2.1) \\
9.8(1.5) \\
8.2(2.2)\end{array}$ & $\begin{array}{c}\text { Mean (SD) } \\
4.3(1.8) \\
2.9(1.2) \\
7.1(2.3) \\
10.2(1.6) \\
8.6(2.3)\end{array}$ & $\begin{array}{c}\text { Mean (SD) } \\
3.9(1.7) \\
2.6(1.2) \\
6.1(2.1) \\
9.6(1.5) \\
7.4(2.1)\end{array}$ \\
\hline $\begin{array}{l}\text { Current drinker (usually one or } \\
\text { more alcoholic drinks) } \\
\text { Overall }\end{array}$ & $\begin{array}{l}\text { Drinker } \\
\text { N (row \%) } \\
552(40.0)\end{array}$ & $\begin{array}{l}\text { Non-drinker } \\
\text { N (row \%) } \\
827(60.0)\end{array}$ & $\begin{array}{l}\text { Drinker } \\
\text { N (row \%) } \\
553(40.7)\end{array}$ & $\begin{array}{l}\text { Non-drinker } \\
\text { N (row \%) } \\
805(59.3)\end{array}$ \\
\hline $\begin{array}{l}\text { Secondary } 1 \text { school-year* } \\
\text { Secondary } 2 \\
\text { Secondary } 3\end{array}$ & $\begin{array}{r}87(20.3) \\
185(39.1) \\
280(58.6)\end{array}$ & $\begin{array}{l}341(79.7) \\
288(60.9) \\
198(41.4)\end{array}$ & $\begin{array}{r}91(20.0) \\
175(38.7) \\
287(63.5)\end{array}$ & $\begin{array}{l}363(80.0) \\
277(61.3) \\
165(36.5)\end{array}$ \\
\hline $\begin{array}{l}\text { Low family affluence } \\
\text { Medium family affluence } \\
\text { High family affluence }\end{array}$ & $\begin{array}{r}61(42.4) \\
202(38.5) \\
289(40.6)\end{array}$ & $\begin{array}{r}83(57.6) \\
322(61.5) \\
422(59.4)\end{array}$ & $\begin{array}{r}57(47.9) \\
207(38.0) \\
289(41.6)\end{array}$ & $\begin{array}{r}62(52.1) \\
338(62.0) \\
405(58.4)\end{array}$ \\
\hline High family affluence & Mean (SD) & Mean (SD) & Mean (SD) & Mean (SD) \\
\hline Premium possessions & $4.5(1.7)$ & $3.9(1.7)$ & $4.4(1.7)$ & $3.7(1.7)$ \\
\hline Standard possessions & $2.9(1.3)$ & $2.7(1.3)$ & $2.8(1.2)$ & $2.7(1.1)$ \\
\hline Dissatisfaction & $6.9(2.2)$ & $6.4(2.1)$ & $6.9(2.3)$ & $5.9(2.0)$ \\
\hline Consumer orientation & $10.1(1.4)$ & $9.7(1.5)$ & $10.1(1.5)$ & $9.5(1.5)$ \\
\hline Brand awareness & $8.9(2.1)$ & $8.0(2.2)$ & $8.4(2.2)$ & $7.3(2.1)$ \\
\hline
\end{tabular}


Table 2 Ever smoking and current drinking according to year group, family affluence, material possessions and Consumer Involvement subscales: unadjusted ORs ${ }^{*}$ (with significance of interaction with gender) and mutually adjusted + ORRs $^{*}$ — males and females

\begin{tabular}{|c|c|c|c|c|c|c|c|c|c|}
\hline & \multicolumn{3}{|c|}{ Unadjusted associations } & \multicolumn{6}{|c|}{ Mutually adjusted associations } \\
\hline & \multirow{2}{*}{$\begin{array}{l}\text { Males } \\
\text { OR (95\% Cls) }\end{array}$} & \multirow{2}{*}{$\begin{array}{l}\text { Females } \\
\text { OR (95\% Cls) }\end{array}$} & \multirow{2}{*}{$\begin{array}{l}\text { (Significance of } \\
\text { interaction with } \\
\text { gender) }\end{array}$} & \multicolumn{3}{|l|}{ Males } & \multicolumn{3}{|l|}{ Females } \\
\hline & & & & OR (95\% Cls) & $\mathbf{t}$ & (Significance) & OR (95\% Cls) & $\mathbf{t}$ & (Significance) \\
\hline \multicolumn{10}{|l|}{ Ever smoker } \\
\hline Secondary 1 school-year & 1.00 & 1.00 & & 1.00 & & & 1.00 & & \\
\hline Secondary 2 & 1.59 (1.05 to 2.40$)$ & $2.24(1.36$ to 3.70$)$ & $(0.226)$ & 1.52 (0.99 to 2.33$)$ & 2.0 & $(0.052)$ & 2.00 (1.22 to 3.27$)$ & 2.8 & $(0.006)$ \\
\hline Secondary 3 & 3.21 (2.23 to 4.62$)$ & 5.52 (3.47 to 8.78$)$ & $(0.034)$ & 3.31 (2.27 to 4.82$)$ & 6.3 & $(0.000)$ & 5.69 (3.56 to 9.10$)$ & 7.3 & $(0.000)$ \\
\hline Low family affluence & 1.00 & 1.00 & & 1.00 & & & 1.00 & & \\
\hline Medium family affluence & $0.69(0.43$ to 1.09$)$ & $0.53(0.35$ to 0.82$)$ & $(0.427)$ & $0.60(0.37$ to 0.98$)$ & -2.1 & $(0.041)$ & $0.51(0.30$ to 0.86$)$ & -2.6 & $(0.011)$ \\
\hline High family affluence & $0.47(0.30$ to 0.76$)$ & $0.52(0.34$ to 0.81$)$ & $(0.760)$ & $0.36(0.22$ to 0.60$)$ & -4.0 & $(0.000)$ & $0.44(0.26$ to 0.75$)$ & -3.0 & $(0.003)$ \\
\hline Premium possessions & $1.08(0.99$ to 1.17$)$ & $1.13(1.04$ to 1.22$)$ & $(0.495)$ & $1.09(0.99$ to 1.18$)$ & 1.9 & $(0.056)$ & $1.12(1.02$ to 1.24$)$ & 2.4 & $(0.018)$ \\
\hline Standard possessions & $1.15(1.03$ to 1.28$)$ & $1.19(1.05$ to 1.33$)$ & $(0.690)$ & $1.19(1.06$ to 1.33$)$ & 3.0 & $(0.003)$ & $1.23(1.09$ to 1.39$)$ & 3.4 & $(0.001)$ \\
\hline Dissatisfaction & $1.13(1.06$ to 1.20$)$ & $1.23(1.15$ to 1.31$)$ & $(0.068)$ & $1.08(1.01$ to 1.15$)$ & 2.2 & $(0.029)$ & $1.11(1.03$ to 1.20$)$ & 2.7 & $(0.007)$ \\
\hline Consumer orientation & 1.18 (1.07 to 1.30$)$ & $1.32(1.19$ to 1.47$)$ & $(0.109)$ & 1.06 (0.94 to 1.18$)$ & 1.0 & $(0.327)$ & 1.09 (0.96 to 1.23$)$ & 1.4 & $(0.173)$ \\
\hline Brand awareness & 1.20 (1.12 to 1.29$)$ & 1.29 (1.21 to 1.39$)$ & $(0.134)$ & 1.17 (1.08 to 1.26$)$ & 4.0 & $(0.000)$ & $1.23(1.14$ to 1.33$)$ & 5.4 & $(0.000)$ \\
\hline$(\mathrm{N})$ & & & & $(1379)$ & & & (1357) & & \\
\hline \multicolumn{10}{|l|}{ Current drinker } \\
\hline Secondary 1 school-year & 1.00 & 1.00 & & 1.00 & & & 1.00 & & \\
\hline Secondary 2 & $2.52(1.84$ to 3.45$)$ & $2.52(1.72$ to 3.69$)$ & $(0.997)$ & 2.49 (1.78 to 3.48$)$ & 5.4 & $(0.000)$ & 2.26 (1.54 to 3.31$)$ & 4.2 & $(0.000)$ \\
\hline Secondary 3 & 5.54 (3.97 to 7.73$)$ & $6.94(4.81$ to 10.01$)$ & $(0.299)$ & 5.87 (4.15 to 8.29$)$ & 10.1 & $(0.000)$ & 7.61 (5.20 to 11.14$)$ & 10.5 & $(0.000)$ \\
\hline Low family affluence & 1.00 & 1.00 & & 1.00 & & & 1.00 & & \\
\hline Medium family affluence & 0.85 (0.59 to 1.24$)$ & $0.67(0.45$ to 0.99$)$ & $(0.371)$ & $0.70(0.46$ to 1.07$)$ & -1.7 & $(0.098)$ & 0.60 (0.39 to 0.92$)$ & -2.4 & $(0.020)$ \\
\hline High family affluence & 0.93 (0.65 to 1.34$)$ & $0.78(0.52$ to 1.16$)$ & (0.493) & 0.66 (0.45 to 0.97$)$ & -2.1 & $(0.036)$ & 0.60 (0.39 to 0.94$)$ & -2.3 & $(0.025)$ \\
\hline Premium possessions & 1.21 (1.13 to 1.30$)$ & $1.26(1.18$ to 1.35$)$ & $(0.429)$ & $1.19(1.10$ to 1.28$)$ & 4.5 & $(0.000)$ & $1.28(1.17$ to 1.40$)$ & 5.6 & $(0.000)$ \\
\hline Standard possessions & $1.15(1.04$ to 1.26$)$ & $1.07(0.96$ to 1.18$)$ & $(0.326)$ & $1.21(1.09$ to 1.34$)$ & 3.7 & $(0.000)$ & $1.13(1.01$ to 1.27$)$ & 2.2 & $(0.029)$ \\
\hline Dissatisfaction & 1.11 (1.05 to 1.16$)$ & 1.24 (1.19 to 1.31$)$ & $(0.002)$ & $1.10(1.03$ to 1.16$)$ & 3.1 & $(0.002)$ & $1.18(1.11$ to 1.25$)$ & 5.6 & $(0.000)$ \\
\hline Consumer orientation & $1.19(1.10$ to 1.28$)$ & $1.30(1.20$ to 1.40$)$ & $(0.089)$ & 1.06 (0.97 to 1.15$)$ & 1.3 & $(0.211)$ & $1.05(0.96$ to 1.15$)$ & 1.0 & $(0.304)$ \\
\hline Brand awareness & 1.21 (1.15 to 1.28$)$ & $1.29(1.22$ to 1.36$)$ & $(0.130)$ & 1.15 (1.08 to 1.23$)$ & 4.4 & $(0.000)$ & $1.21(1.13$ to 1.30$)$ & 5.6 & $(0.000)$ \\
\hline$(\mathrm{N})$ & & & & (1379) & & & (1358) & & \\
\hline
\end{tabular}


drinking than did 'premium' possessions or 'brand awareness'. Among females, it also had a less significant relationship with smoking than 'brand awareness'. Further analyses, conducted in respect of different measures of smoking and drinking also found that among females, current smoking (reported by only $6.7 \%$ males and $8.9 \%$ females) had a stronger relationship with 'brand awareness' than with family affluence, and that among both genders, ever drinking, which was very frequently reported ( $86 \%$ males, $86.8 \%$ females), had a stronger relationship with 'brand awareness' than with family affluence (see online supplementary table S3).

Finally, further investigation of the interaction between 'consumer orientation' and family affluence in respect of current drinking found that it was not significant in analyses conducted on males and females separately. In the sample as a whole, the ORs (and 95\% CIs) of drinking in respect of a one-unit increase in 'consumer orientation' among those from low, medium and high family affluence households were 1.45 (1.24 to 1.70$), 1.23$ (1.13 to 1.34 ) and 1.22 (1.12 to 1.32 ), respectively.

\section{DISCUSSION}

As highlighted by our data, early adolescence is a period of rapid increase in the prevalence of both smoking and drinking. Understanding influences on uptake of these behaviours during this period is therefore crucial. We found that rates of both smoking (ever) and drinking (one or more alcoholic drinks on a usual occasion) were higher among more consumerist Scottish early adolescents, as measured by a range of indicators. Thus, both behaviours were more likely among those who possessed more modern electronic gadgets and consumer goods, regardless of whether these were 'standard' or potentially more desirable 'premium' items. Rates of smoking and drinking were also higher among more 'dissatisfied', 'consumer orientated' and 'brand aware' adolescents. Relationships between our consumerism measures and both smoking and drinking were largely similar for males and females and for those from less affluent compared with more affluent households.

In line with other recent UK studies which have found evidence of higher levels of smoking among adolescents from lower socio-economic status (SES) backgrounds, but little or no social gradient in adolescent drinking, ${ }^{28}{ }^{29}$ we found much clearer differences according to family affluence for smoking than drinking. Indeed, family affluence had a weaker relationship with drinking (both ever and current) than did several of our consumerism measures, and an equal (males) or weaker (females) relationship with smoking (ever and current) than 'brand awareness'. These results therefore highlight the importance of focusing on not only socio-economic, but also cultural factors in relation to health, ${ }^{7}$ at least in adolescence.

The social patterning of smoking and (harmful) drinking are important contributors to socio-economic and gender inequalities in health. For example, it has been estimated that across 30 European countries, smoking accounts for around 40-60\% of gender differences in life expectancy and drinking for $10-30 \% .^{25}$ As the UK is well advanced in the smoking epidemic, ${ }^{30}$ current smoking is increasingly concentrated in people from lower socio-economic groups. For these reasons it is important to examine whether contemporary cultural influences on smoking and drinking differentially affect males compared with females, or those from lower compared with higher SES backgrounds, particularly at an age when experimentation with and uptake of these behaviours is so widespread. Any differential impacts could alert us to future trends in inequalities and/or indicate whether interventions need to be targeted to particular subgroups. It is thus of interest to note the general lack of differential effects by both gender and family affluence, although we did find suggestions of slightly stronger associations between the Consumer Involvement subscales, particularly 'dissatisfaction', and both smoking and drinking among females.

Our analysis was conducted on a large sample of early adolescents attending mainstream schooling. Comparison of our sample with the 2010 WHO Health Behaviours in School-aged Children (HBSC) Scottish survey shows very similar levels of family affluence $(52 \%$ high affluence, $39 \%$ medium and $10 \%$ low affluence in our dataset; $53 \%$ high, $35 \%$ medium, $9 \%$ low, $3 \%$ missing in HBSC) and current smoking (18\% among S2 pupils in our dataset, $19 \%$ in HBSC; measures of drinking used in the two studies are not sufficiently similar to compare directly). ${ }^{31}$ The authors of our measure of family affluence note that it shows validity both in respect of agreement between pupils and parents on the component items, and in its relationship with other measures of SES such as parental occupation and country-level macroeconomic indicators such as GDP. ${ }^{27}$ However, since it is based on family vehicles, bedrooms, computers and holidays, it is possible that the scale is, at least in part, a measure of (family) consumerism in addition to affluence.

Cross-sectional data limit definitive conclusions about causation. However, we believe that a more plausible hypothesis for future longitudinal analyses is that consumerist attitudes lead to uptake of smoking and drinking rather than the reverse. It is also possible that the relationships which we have identified are the result of confounding by additional factors (such as negative affectivity). However, this is likely to be more of an issue in studies of consumerism and well-being.

Our results are consistent with the small number of other studies which have found associations between consumerist values and adolescent substance use. ${ }^{15-18}$ However, previous studies have not examined whether particular aspects of consumerism might have stronger associations with substance use than others. Relationships between smoking and drinking and the Consumer Involvement subscale 'dissatisfaction' support suggestions by other authors that substance use might be an attempt to satisfy the unmet needs of more materialistic 
individuals. ${ }^{15}{ }^{17}$ However, we also found that smoking and drinking were most strongly associated with 'brand awareness' (comprising items emphasising the importance of brand names, popular labels and being cool), and also with possession of modern consumer goods. This, together with evidence from other studies that 'brand awareness' has strong relationships with cinema-going, internet use, chat room visits, listening to music and TV-watching among early adolescents, ${ }^{13}$ and that smoking is associated with fashion-consciousness, particularly among young women, ${ }^{32}$ suggests that image and identity may be important mechanisms linking consumerism with these two aspects of adolescent substance use.

The association may also be the result of indirect or direct promotion linking consumerist or aspirational lifestyles with smoking or drinking. Previous studies have highlighted the influence of tobacco and alcohol marketing on young people's smoking ${ }^{33} 34$ and drinking. ${ }^{35}$ Patterns of association between consumerism and both smoking and drinking (whether defined as 'ever' or 'current') were very similar, despite the fact that within the UK, direct advertising of alcohol is permitted, while that of tobacco is prohibited. However, distinctive marketing of tobacco products persists via packaging and point of sale displays, and the entertainment media continues to portray many largely positive representations of smokers in films. ${ }^{36}$ Such images have been shown to be associated with young people's health behaviours. ${ }^{37-40}$ Marketing is designed to develop and sell brands, thus both increasing consumption and establishing the credibility and legitimacy (normalising) of products or behaviours; ${ }^{41}$ indeed, to be successful, marketing has to foster aspirations to buy and to consume. More consumerist children and adolescents have been found to be more susceptible to advertising and promotion. ${ }^{42}$ Our study suggests this may also include both the subtle marketing and imagery used by tobacco companies and the stronger direct marketing used by drinks manufacturers.

Acknowledgements The authors would like to thank Robert Young, who conducted the confirmatory factor analyses and Sally Macintyre for her comments on an earlier version of this paper. Acknowledgements are also due to Juliet Schor, whose 'Consumer Involvement' scale we used, and to the young people, schools and all those from the MRC Social and Public Health Sciences Unit involved in the 'Adolescent Lifestyles in Contemporary Europe' ('ALICE') study.

Contributors $\mathrm{KH}$ and HNS contributed to the study design, all authors contributed to the data collection and $A B$ cleaned the data. HNS conducted the analyses, drafted and revised the paper and is the guarantor. $\mathrm{KH}$ and $\mathrm{AB}$ drafted and revised the paper.

Funding This work was funded and sponsored by the UK Medical Research Council as part of the Gender and Health Programme at the Social and Public Health Sciences Unit (project code MC_A540_5TK50).

Competing interests None.

Ethics approval University of Glasgow Faculty of Law, Business and Social Sciences Ethics Committee, participating local education authorities and schools.

Provenance and peer review Not commissioned; externally peer reviewed.

Data sharing statement We welcome opportunities to collaborate with colleagues who wish to analyse 'ALICE' data. Please contact the corresponding author for further information.

\section{REFERENCES}

1. NHS Information Centre. Statistics on alcohol: England, 2011 Leeds: The Information Centre for Health \& Social Care, 2011.

2. Allender $S$, Balakrishnan R, Scarborough $P$, et al. The burden of smoking-related ill-health in the UK. Tobacco Control 2009;18:262-7.

3. Lynch B, Bonnie R. Growing up tobacco free-preventing nicotine addiction in children and youths: a report of the Institute of Medicine. Washington, DC: National Academy Press, 1994.

4. British Medical Association-Board of Science. Under the influence: the damaging effect of alcohol marketing on young people. London: The British Medical Association, 2009.

5. Eckersley R. Is modern Western culture a health hazard? Int $J$ Epidemiol 2006;35:252-8.

6. Hanlon P, Carlisle S. Is 'modern culture' bad for our health and well-being? Global Health Promot 2009;16:27-34.

7. Eckersley R. A new narrative of young people's health and well-being. J Youth Stud 2011;14:627-38.

8. Belk R. Three scales to measure constructs related to materialism: reliability, validity and relationships to measures of happiness. Adv Consumer Res 1984;11:291-7.

9. Richins ML, Dawson S. A consumer values orientation for materialism and its measurement: scale development and validation. $J$ Consumer Res 1992;19:303-16.

10. Sirgy MJ. Materialism and quality of life. Soc Indicators Res 1998;43:227-60.

11. Schor J. Born to buy. New York: Scribner, 2004

12. Flouri E. Exploring the relationship between mothers' and fathers' parenting practices and children's materialist values. J Econ Psychol 2004;25:743-52.

13. Bottomley P, Nairn A, Kasser T, et al. Measuring childhood materialism: refining and validating Schor's Consumer Involvement Scale. Psychol Mark 2010;27:717-40.

14. Sweeting $\mathrm{H}$, Hunt $\mathrm{K}$, Bhaskar A. Consumerism and well-being in early adolescence. J Youth Stud 2012;15:802-20.

15. Williams GC, Cox EM, Hedberg VA, et al. Extrinsic life goals and health-risk behaviours in adolescents. $J$ Appl Soc Psychol 2000;30:1756-71.

16. Kasser T. Frugality, generosity, and materialism in children and adolescents. In: Moore KA, Lippen LH, eds. What do children need to flourish? Conceptializing and measuring indicators of positive development. New York: Springer, 2005:357-73.

17. Vansteenkiste M, Duriez B, Simons J, et al. Materialistic values and well-bring among business students: further evidence of their detrimental effect. J Appl Soc Psychol 2006;36:2892-908.

18. Auerbach RP, McWhinnie CM, Goldfinger M, et al. The cost of materialism in a collectivistic culture: predicting risky behavio engagement in Chinese adolescents. J Clin Child Adolesc Psychiatry 2010;39:117-27.

19. Chaplin LN, John DR. Growing up in a material world: age differences in materialism in children and adolescents. J Consumer Res 2007;34:480-93.

20. La Barbera PA, Gurhan Z. The role of materialism, religiosity, and demographics in subjective well-being. Psychol Mark 1997;14:71-97.

21. Ennett ST, Bauman KE, Hussong A, et al. The peer context of adolescent substance use: findings from social network analysis. $J$ Res Adolesc 2006;16:159-86.

22. Coleman L, Cater S. Changing the culture of young people's binge drinking: from motivations to practical solutions. Drugs Educ Prev Policy 2007;14:305-17.

23. Emslie C, Lewars H, Batty GD, et al. Are there gender differences in levels of heavy, binge and problem drinking? Evidence from three generations in the west of Scotland. Public Health 2009;123:12-14.

24. Sweeting H, Jackson C, Haw S. Changes in the socio-demographic patterning of late adolescent health-risk behaviours during the 1990s: analysis of two West of Scotland cohort studies. BMC Public Health 2011;11:829.

25. McCartney G, Mahmood L, Leyland A, et al. Contribution of smoking-related and alcohol-related deaths to the gender gap in mortality: evidence from 30 European countries. Tobacco Control 2011;20:166-8.

26. Burroughs JE, Rindfleisch A. Materialism and well-being: a conflicting values perspective. J Consumer Res 2002;29:348-70.

27. Currie C, Molcho M, Boyce W, et al. Researching health inequalities in adolescents: the development of the Health Behaviour in School-Aged Children (HBSC) family affluence scale. Soc Sci Med 2008;66:1429-36.

28. Brooks F, van der Sluijs W, Klemera E, et al. Young people's health in Great Britain and Ireland: findings for the health behaviour in School-Aged Children Survey 2006. Edinburgh: HBSC International Coordinating Centre, Child and Adolescent Health Research Unit (CAHRU), 2009 
29. Information and Statistics Division Scotland. Scottish Schools Adolescent Lifestyle and Substance use Survey (SALSUS) National Report 2008. Edinburgh: Scottish Executive, 2009.

30. Lopez AD, Collishaw NE, Piha T. A descriptive model of the cigarette epidemic in developed countries. Tobacco Control 1994;3:242-7.

31. Currie C, Levin K, Kirby J, et al. Health behaviour in school-aged children Scotland National Report: findings from the 2010 HBSC survey in Scotland. Edinburgh: University of Edinburgh Child and Adolescent Health Research Unit, 2011.

32. Wearing $\mathrm{S}$, Wearing B. Smoking as a fashion accessory in the 90s: conspicuous consumption, identity and adolescent women's leisure choices. Leisure Stud 2000;19:45-58.

33. Moodie C, Mackintosh AM, Brown A, et al. Tobacco marketing awareness on youth smoking susceptibility and perceived prevalence before and after an advertising ban. Eur J Public Health 2008;18:484-90.

34. Hoek J, Gendall P, Gifford H, et al. Tobacco branding, plain packaging, pictorial warnings, and symbolic consumption. Qual Health Res 2012;22:630-9.

35. Gordon R, Harris F, Mackintosh AM, et al. Assessing the cumulative impact of alcohol marketing on young people's drinking: cross-sectional data findings. Addict Res Theory 2011;19:66-75.
36. Dalton MA, Tickle JJ, Sargent JD, et al. The incidence and context of tobacco use in popular movies from 1988-1997. Prev Med 2002;34:516-23.

37. Sargent JD, Beach ML, Adachi-Mejia AM, et al Exposure to movie smoking: its relation to smoking initiation among US adolescents. Pediatrics 2005; 116:1183-91.

38. Morgenstern M, Poelen EA, Scholte R, et al. Smoking in movies and adolescent smoking: cross-cultural study in six European countries. Thorax 2011;66:875-83.

39. Hunt K, Henderson M, Wight D, et al. Exposure to smoking in films and own smoking amongst Scottish adolescents: a cross-sectional study. Thorax 2011;66:866-74.

40. Hanewinkel R, Sargent JD, Poelen EAP, et al. Alcohol consumption in movies and adolescent binge drinking: cross-sectional study in six European countries. Pediatrics 2012;129:709-20.

41. Wolberg JM. Condoms, cigarettes, and cell phones: does brand advertising increase generic demand? J Product Brand Manag 2008;(17):285-6.

42. Goldberg ME, Gorn GJ, Peracchio LA, et al. Understanding materialism among youth. J Consumer Psychol 2003; 13:278-88. 